\title{
Opium Addiction among Rural Population in Desert Districts of Western Rajasthan: Some Observations from the Study
}

\author{
J. Lakshminarayana and Madhu B. Singh
}

Desert Medicine Research Centre, ICMR, New Pali Road, Jodhpur, Rajasthan, India

KEYWORDS Opium Addiction. Desert Population. Rural Areas. Western Rajasthan

\begin{abstract}
A house to house survey was done in 45 rural villages of Barmer, Jaisalmer and Bikaner districts of Rajasthan. A total of 1200 house holds were screened interviewed and data was collected on schedules. The analysis revealed that there were 1200 opium or doda addicts in the rural population of 3640 . The over all addiction rate was $8.4 \%$ in Barmer , $79 \%$ in Jaisalmer and $6.9 \%$ in Bikaner districts of Rajasthan. The addicts were all males and a negligible number of females $(0.3 \%)$ in the surveyed villages. The rate of addiction was increasing as age is increasing and showed significant increase $(\mathrm{P}<0.05)$ in consumption there by more population is getting addicted to the substance. The addiction was highest in the age group 40-50 years compared to the other age groups. The literacy and low socioeconomic status are the major causes for addiction $(\mathrm{P}<0.05)$ which is statistically significant, as they were having poor knowledge of its ill effects over time. The reasons for consumption are to work more in the fields and to get rid of minor ailments and in due course of time they become addicts. The significance of these findings and factors causing a grate concern, about the opium or doda addiction in the rural villages and measures to de-addict the rural population, recurrence rates are discussed.
\end{abstract}

\section{INTRODUCTION}

The opium and doda (which is the powdered form of dried poppy fruit supplied by Govt. as rationing for notified persons (addicts) which is being consumed by mixing in water in the rural areas of desert especially in western Rajasthan) botanically opium is know as Papaver somniferum which is available in chocolate colored gum form prepared by drying the poppy fruit milk on a cotton cloth in the hot sun. Since ancient times opium used by Rajput (warrior) clan of this part of the country particularly in the desert part mainly to reduce bleeding and allay apprehension during war times. It was also used since long as a mind altering drug and as an analgesic on the indo-Pakistan sub-continent as reported by (Dwarakanath 1965; Kohli 1966). In the beginning opium use was restricted elite class of the society in addition to its use in the traditional system of medicine. In many parts of India opium is being given by sticking to the upper palate to young Infants to make them sleep so that, their mothers can go to work in the agricultural fields and labor work and besides this, opium has also being

Corresponding Author:

Dr. J. Lakshminarayana, M.Sc., Ph.D, FRSS(UK)

Assistant Director (Statistics), Desert Medicine Research

Centre, ICMR, Jodhpur 342 005, Rajasthan, India

Telephone: 0291- 2722403 (O), 0291-2745454 (R )

Fax: 0291-2720618

E-mail: lakshmi_nj@rediffmail.com used as ceremonial drink during the vital events in the village during festivals and social functions in the rural village. Now the opium use is not restricted any caste or creed it finds social sanction and it is not considered as an evil. (Purohit 1982; Purohit et al.1988).

The literature review reveals that the recent systematic studies of opium use in rural population is very scanty. In a survey conducted in rural Punjab population the authors (Kohli D.N, 1966) reported $5.7 \%$, as the prevalence rate of opium use in desert is significantly higher in men than women in desert part which is around 8.0\% reported (Mathur et al. 1991; Lakshminarayana et al. 2000).

The main aim of the present paper is to estimate the prevalence of opium and doda consumption and thereby getting addicted and to highlight the magnitude of the opium or doda addiction in the rural areas of Desert part of Rajasthan and factors generating the concern about the increasing addiction among the rural desert population of western Rajasthan.

\section{MATERIAL AND METHODS}

The present study was conducted in 45 rural villages of desert districts of Rajasthan concluded in 2000. After gathering information regarding the increasing trend of opium consumption which is leading to addiction in the rural areas of desert. The present study was conducted with the 
objective to determine the prevalence of opium addiction and other substances like smoking and alcohol consumption. The hypothesis of the study is that the socio cultural factors do influence the opium consumption leading to addiction among the communities and therefore the social profile of opium consumers is expected to be different from those of non- consumers in rural areas of desert Rajasthan.

A house to house survey was carried out and covered a total of 1200 house holds in the selected villages of desert districts which were selected based on the prevalence figures available in the literature, based on the figures sample size was calculated by the formula $n=(4 * \mathrm{P} * \mathrm{q}) / \mathrm{L} * 2$ where $\mathrm{p}$ is the prevalence and $\mathrm{q}$ is $(1-\mathrm{p})$ and $\mathrm{L}$ is allowable error with $95 \%$ confidence interval. The data collected on pre-designed schedule from the opium or doda addicted persons. The data regarding other addicts were also obtained from one addict by using Simple random sampling technique as all the addicts will gather at one place in the village and consume opium and smoke chilam. Visited every house and noted the information. Only one member in the family was the addict in all the surveyed villages. The age, gender and other demographic and socioeconomic data of opium addict and other male members of the house has been recorded. In this manner a total of 1200 addicts and 1200 non addicts were interviewed and data has been collected from the rural population. The data was entered in the computer by using FOX-PRO programme and analysed using EPI-INFO soft ware and Chi- Square test, t-test were used for significance, as applicable.

After having discussions with the village surpanch or village head about this social evil (opium or doda addiction) and its deleterious effects upon the health of the individual and economy of the community as a whole then the survey was started with th consent of the villagers. The individuals were made aware of the ill effects of the opium or doda addiction and were explained that it is possible to leave opium easily and smoothly with the help of the medical treatment. The local villager was along with us during the data collection to communicate the message properly in local language. Keeping in view of the hardships of high temperatures and desert conditions still we made it possible to contact all mot all the addicted subjects available in the village by Simple Random Sampling technique and collected required sample and information/data about the demographic and socio-economic parameters and the recurrence rates were calculated

The term consumer is used in this paper, as the one who is taking/having opium or doda since five years with friends during the festivals and Social gatherings. An addict is the one who is dependant and cannot live with out it according to the international classification of Diseases (WHO, Mental Disorders 1999 Category for drug dependency).

\section{RESULTS}

\section{Relationship of Opium Addiction with Age}

It is observed that majority of the opium addicts were aged between 40 to 50 years (Table 1) and the highest Prevalence rate 8.4 years which was in Barmer district. the age group of $40+$ years was observed to be crucial for addicts. The Barmer district showed highest prevalence of $8.4 \%$ followed by Jaisalmer 7.9\% and Bikaner 6.9\% No addicts/consumers were found below 20 years of age. The prolonged duration of consumption (>!0 Years) then the subjects become addicted to the opium or other substances that means duration of consumption plays vital role in becoming addiction. Rajput, choudhary/jat and vishnoi castes are major consumers and thereby becoming addicts in the rural areas of western Rajasthan. Education play a vital role in opium addiction. The educated person is very much aware of the ill effects of opium./ doda consumption which is statistically significant $(\mathrm{P}<0.05)$.

Table 1: Distribution of opium addicts according to age groups and in desert districts (pooled)

\begin{tabular}{lcc}
\hline $\begin{array}{l}\text { Age } \\
\text { group }\end{array}$ & $\begin{array}{c}\text { Opium addicts } \\
N=(1200)\end{array}$ & $\begin{array}{c}\text { Chronic smokers } \\
N=(600)\end{array}$ \\
\hline$<30$ & 8.4 & 6.6 \\
$30-40$ & 26.5 & 30.5 \\
$40-50$ & 41.8 & $50.1 *$ \\
$50-60$ & 26.1 & 8.6 \\
$>60$ & 7.2 & 4.2
\end{tabular}

* - $\mathrm{P}<0.05$

Table 2: Prevalence rates among different districts with average age and standard deviations.

\begin{tabular}{lccc}
\hline \multirow{2}{*}{$\begin{array}{l}\text { Study } \\
\text { districts }\end{array}$} & \multicolumn{2}{c}{ Average age } & Prevalence \\
\cline { 2 - 3 } & Mean & S.D. & \\
\hline Barmer & 40.4 & 8.28 & 8.4 \\
Jaisalmer & 38.2 & 9.44 & 7.9 \\
Bikaner & 39.3 & 6.45 & 6.9 \\
\hline
\end{tabular}


Table 3: Distribution subjects according to opium alcohol and smoking addiction as per major caste groups

\begin{tabular}{|c|c|c|c|c|c|c|}
\hline \multirow[t]{2}{*}{ Caste groups } & \multicolumn{2}{|c|}{ Opium (1200) } & \multicolumn{2}{|c|}{ Alcohol (600) } & \multicolumn{2}{|c|}{ Smoking (600) } \\
\hline & No. & $\%$ & No. & $\%$ & No. & $\%$ \\
\hline Rajputs & 502 & 41.8 & 240 & 40.0 & 301 & 50.2 \\
\hline Choudhary/Jat & 218 & 26.5 & 205 & 34.2 & 183 & 30.5 \\
\hline Vishnois & 193 & 16.1 & - & - & - & - \\
\hline LowerCaste & 125 & 10.4 & 121 & 20.2 & 91 & 15.2 \\
\hline Others & 62 & 5.2 & 34 & 5.7 & 25 & 4.2 \\
\hline
\end{tabular}

Average consumptions: Opium: 12 gms, Doda: 200 gms, Alcohol: 250 gms. Chilam: 20 gms,

Smoking Beeris: 25 Nos. per day

\section{DISCUSSION}

The present study is one of its kind conducted in rural population of desert districts of western Rajasthan. The analysis revealed that that $8.9 \%$ prevalence in Barmer, $7.9 \%$ in Jaisalmer and 6.9\% prevalence in Bikaner districts of western Rajasthan (Table 2). The overall addiction was significantly higher $(\mathrm{P}<0.05)$ in the desert districts as compared to other rural areas of India. However the opium users were being categorized into experimental, seasonal and regular types in Punjab survey showing $3.6 \%$ prevalence rate for men in the regular opium group (Mohan D, Sharma HK and Sundaram KR, 1979). In Himachal pradesh survey on tribal population the prevalence was around $20.4 \%$ which is very high as compared to regular opium users (WHO: Mental Disorders 1999): The rate of opium addiction is increasing progressively with age $(\mathrm{P}<0.05)$ till about midfifties and showed a declining trend after wards.

The various factors causing concern about the opium addiction among the villagers were progressive deterioration of health , to meet the increasing cost of the opium the addicts had been mortgaging their valuable things and ornaments to the opium traders in lieu of opium. At times they restored to stealing which gave rise to intra

Table 4: Distribution of addict according to literacy status

\begin{tabular}{lrrrcc}
\hline $\begin{array}{l}\text { Literacy } \\
\text { status }\end{array}$ & \multicolumn{2}{c}{$\begin{array}{c}\text { Non addicts } \\
N=(1200)\end{array}$} & & \multicolumn{2}{c}{$\begin{array}{c}\text { Opium addicts } \\
N=(600)\end{array}$} \\
\cline { 2 - 3 } \cline { 5 - 6 } & No. & $\%$ & & No. & $\%$ \\
\hline Illiterate & 961 & 80.1 & & 482 & $80.3 *$ \\
Literate & 127 & 10.6 & & 43 & 7.3 \\
Primary & 70 & 5.8 & & 32 & 5.3 \\
Middle & 19 & 1.6 & & 23 & 3.8 \\
Secondary & 12 & 1.0 & & 10 & 1.7 \\
Hig. Sec. & 11 & 0.9 & & 8 & 1.3 \\
College & 0 & & & 2 & 0.3 \\
\hline
\end{tabular}

$*_{-} \mathrm{P}<0.05$ familial tension and fights. The addicts harbored a fear that their children may not fall in the same ditch of addiction. The social relations of these rural population were being spoiled because of opium addiction and people out side the village are preferred not to marry their daughters in these families because of social stigma. The Rajput caste group is dominating and are more addicted than choudhary and other caste group Majority were illiterates(>80.\%) (Table 3,4) and significantly higher when compared with literacy status $(\mathrm{P}<0.05)$ agriculture labor is the occupation of these addicts. There are lot of NGO activities for de-addiction in these areas but people are afraid of going to these centers because lack of proper health facilities during de-addiction The main reason is that one may feel that thy may die if they go for de-addiction camp. The recurrence rate was around $4 \%$ out of the de-addicted subjects. They start consuming due to old friends offer them and due to environmental factors which plays major role in consumption again.

\section{CONCLUSION}

It is concluded that from these observations that rural desert population in western Rajasthan is highly addicted with male opium addicts and this addiction rate is increasing progressively with age till about mid-fifties. Some authors (Drug Abuse in India,) claim that the number of opium addicts are limited because of good control of opium poppy cultivation in India. The present survey however, indicates that in spite of adequate control measures, good amounts of opium is still available in the rural areas of desert Rajasthan (Mathur et al. 1991; Mohan et al. 1979) which might be reaching to the people through illegal trafficking. It needs all out efforts to root out this evil problem.

The department of health, social welfare and 
voluntary organisations should come forward for de-addiction camps at tehsil level and stop the availability of opium or doda to the people to preserve the health and economy of the country and nation as a whole.

The average consumption of opium calculated as $12 \mathrm{Gms} /$ day per subject and is sold in the rural areas at the rate of rurpees $30 /=$ per tola (i.e., $10 \mathrm{gms}$ for 30 rupees.) doda is $200 \mathrm{gms} /$ day and alcohol is $250 \mathrm{ml}$. /day and they smoke at the beeris at the rate of 25 nos. per day per individual. Majority of the addicts are Illiterates $(80 \%)$

only $20.0 \%$ are literatures who knows about the ill effects of opium consumption and smoking. This clearly Shows that lack of Intervention Education and communication (IEC) activities which are to be enhanced by govt. Depts. in the rural areas of far flung areas of desert where there is no adequate Agricultural work and labor work.

It is concluded that from these observations that rural desert population in western Rajasthan is highly effected with male addicts and this addiction rate is alarmingly increasing in Arithmetic progression with age till about midfifties.

Some authors and WHO drug abuse, WHO mental disorders, claim that the number of opium addicts are limited because of good control of opium poppy cultivation in India but present study reveals that still it is in increasing trend in tropical areas of desert Rajasthan. This has to be stopped to improve the health and wealth of the people in th rural areas.

\section{ACKNOWLEDGEMENTS}

The authors are very grateful to Sh. Rajnesh kumar and Santosh Dhawal for their work in data collection and al those workers who helped for translation in the villages while collecting information.

\section{REFERENCES}

Chopra GS. 1972. Sociological and economic aspects of drug dependence in India. Int J Addiction, 7: 57-63.

Drug Abuse in India 1977. Report of Committee Appointed by the Government of India, Ministry of Health and Family Welfare, Govt. of India, New Delhi.

Dwarakanath C 1965. Use of opium and cannabis in the traditional system of medicine in India, Bull Narct, 27: 13-19.

Kohli DN 1966. The study of narcotic control in India, Bull Narct, 18: 3-12.

Lakshminarayana J, Misra KN, Kalundha RK 2000. Opium consumption and Fecundability Proc. of Conference of Indian Society for Medical Statistics (ISMS). Pp. 277-288.

Mathur ML, Bansal RK, Dixit A 1991. Prevalence of opium consumption in rural population of a desert district Jodhpur. Ind J Pub Heal, XXXV(4): 117-18.

Mohan D, Sharma HK, Sundaram KR 1979 Pattern and prevalence of opium use in rural Punjab (India). Bull Narc, 31: 45-56

Purohit DR, Vyas BR 1982. Opium addiction treatment camp - a follow up study. J Clin Psy India, 6(1): 55.

Purohit DR 1988. community approach to opium dependent subjects in rural areas of Rajasthan. $J$ Comm Psy, 11(2): 3.

World Health Organization: Mental Disorders 1999. Glossary and Guide to their classification in accordance with the tenth revision of International classification of Diseases. Geneva: WHO. 